Ich überreiche den mit Wissenschaften Vertrauten und denen, welcbe sich mit der Arabischen Sprache und Litteratur bekannt machen wollen, ein Buch, woran ich viele Jahre gesammelt habe und wünsche, dass es mit dem Eifer aufgenommen werde, mit dem es gemacht ist. Zuerst wollte ich es über das ganze Feld der Arabischen Litteratur ansbreiten und hatte schon sehr viel dafür gesammelt; allein je mehr ich in den Jahren fortrückte, desto mehr sah ich ein, dass dieses unmöglich sei, denn wie sollte ich mir die nöthigen Hülfsmittel verschaffen, wie sollte ich die Zeit gewinnen, sie durchzulesen? Und da ich vor einigen Jahren krank ward, über drei Vierteljahre das Zimmer hüthen musste und mir ein eifriges Studium von den A ertzten für immer untersagt ward, da war es mit diesem anhaltenden Studium ein Ende. Doch dasjenige liegen und vergehn zu lassen, woran ich so lange gearbeitet hatte, schien mir sündlich zu sein; besonders da noch kein Buch dieser Art vorhanden war und mancher mit dem Studium anfängt, doch bald dasselbe wieder unterlässt, weil er über den Umfang desselben nicbt gehörig unterrichtet war. Dann hat er eine Zeit verlohren, die er nützlicher für sich hätte anwenden können. Allein nicht blos für die, welche das Arabische treiben oder treiben wollen, ist dieses Buch geschrieben; sondern für alle, denen Wissenschaft am Herzen liegt, denn sehr wenige sind, die das Arabische Leben im Genauen kennen. Ich hatte zwar vicles aus der spätern Zeit gesammelt; allein dieses liess ich liegen, weil ich nichts Vollständiges darüber geben konnte. Nur in einzelnen Dingen musste ich die spätere Zeit mit dex füuhern rereinigen, weil ich hauptsächlich spätere Schriftsteller gebrauchen konnte und keine hatte, die über Mohammed hinausgingen, denn die frühern Gedichte, so weit sie uns bekannt sind, geben nichts davon an. Einiges auch von p. $125-133^{\circ}$ hatte ich viel vollständiger gesammelt; allein hicr zwangen mich die Kosten des Drucks abzukürzen, so viel es mir möglich schien. Man wird mir vielleicht vorwerfen, dass ich nicht das Leben der Nomaden von den Stadtbewohnern genug geschieden habe; allein dieses war nicht möglich, weil die Arabischen Schriftsteller es selbst nicht gethan haben. Wo ich aber aus der spätern Zeit etwas beibrachte, geschah es in der Regel nur dann, wenn es zu dem Frühern in Bezug stand. Unmöglich aber ist es, die 
spätere Zeit ganz genau von der frühern zu scheiden, weil wir, darüber keinc historischen Berichte haben.

In den Arabischen Sprichwörtern Tom. III T. 2. p. 68, wo ich dieSprichwörter nach der Zeit ihrer Entstehung angeführt habe, sind vicle aus der Zeit vor Mohammed von Lokwan dem Aldditen, vom Lokaim, vom weisen Lokman, von Moahwijiah dem Fürsten der Amalekiten, von einem unbekannten Könige der Hirijariten, von einem Könige der Ghassaniden, von Cosroes und zu seiner Zeit aufgekommen, vom Albarets ben-Ahmru dem Könige von Cendah, von $\mathrm{Ha}$ tim Thai, von Colaib Wajel, vom Ahmru-l'Kàis ben-Hodjr, vom Nolıman beni-Mäissema, vom Ahmru ben-Nohman, vom Almondsir ben-Mäissema und Nohman ben-Mondsir, dann von Mohammed und den vier Chalifen etc., dann die berühmten Schlachttage T. III T. I p. 553 ff., dann die zur Zeit des Islams entstandenen p.593-606, dann berïhmte Worte Mohammeds, der vier Nachfolger im Chalifate und einiger anderer p. 607 -655. Ueber die Monate dea ältern Zeit bei den Arahern kann man Golius ad Alferganium und Pocock specimen historiac Arabum p. 181 ff. und eine $\mathrm{Ab}$ handlung des 14. Bandes der Zeitschrift deutsch morgenländische Gesellschaft nachsehen.

Da ich wünsche, dass dieses Buch auch von denen gebraucht werde, welche nicht llebräisch und $\Delta$ rabisch wissen, so babe ich von dem Hebräischen und Arabischen Alphabete so viel als nothwendig ist, um einzelne Würter lesen zu künnen, zugesetzt

\section{Hehräische Buchstaben.}

Alef $\ltimes$ Aa Brustthon, starker, wenn er im Anfange der Sylbe stcht, wie רas Amar; schwächer, wenn er am Ende stcht, wic דic Huã.

Bet ב B בריד Bārād

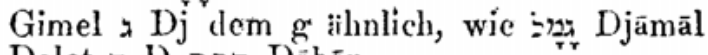

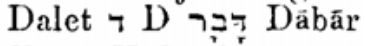

Ile - H Stärker, wenn es_im $\Lambda$ nfange der Sylbe steht, wie הוא Hua; schwächer, wenn es am Ende stcht, wie בָָָּה Mātāh

Waw, W Wenn es im Anfange der Sylbe steht wie W. z. B. ᄀ? Wālad oder wie O oder U, wenn es in der Mittc steht z. B. הוֹד Hōd oder היפ Hūm auszusprechen

Säin ז Weiches_Ds, wie ז̀ Dsōbar

Chet $\pi$ Starkes und volles Ch 